\title{
A importância do farmacêutico no ciclo da Assistência Farmacêutica
}

\section{The importance of the pharmacist in the Pharmaceutical Service cycle}

Ana Elisa Prado Coradi

O artigo de Silva Júnior e Nunes, publicado neste fascículo, "Avaliação da assistência farmacêutica na atenção primária no município de Petrolina (PE)"1 mostra uma realidade de vários municípios no Brasil, onde o ciclo da Assistência Farmacêutica não é executado em sua totalidade, interferindo, assim, em todo o sistema de saúde do município e qualidade de vida da população.

De acordo com a Política Nacional de Medicamentos (PNM), instituída pela Portaria do Ministério da Saúde nº 3.196/1998, a Assistência Farmacêutica é parte integrante e indispensável para a efetividade do Sistema Único de Saúde (SUS) ligada à execução das ações da assistência à saúde da população².

A concepção mais elaborada da Assistência Farmacêutica deve-se ao Conselho Nacional de Saúde (Resolução CNS n 338/2004), o qual define:

Assistência Farmacêutica trata de um conjunto de ações voltadas à promoção, proteção e recuperação da saúde, tanto individual como coletivo, tendo o medicamento como insumo essencial e visando o acesso e a seu uso racional. Este conjunto envolve a pesquisa, o desenvolvimento e a produção de medicamentos e insumos, bem como a sua seleção, programação, aquisição, distribuição, dispensação, garantia de qualidade dos produtos e serviços, acompanhamento e avaliação de sua utilização, na perspectiva da obtenção de resultados concretos e da melhoria da qualidade de vida da população ${ }^{3}$.

No ciclo da Assistência Farmacêutica, o resultado de uma atividade é o ponto de partida para outra e a ausência ou a execução de forma inadequada de uma delas, acaba impedindo o correto funcionamento de todo o ciclo ${ }^{1}$.

As etapas do ciclo da Assistência Farmacêutica (Figura 1) são $o^{2-4}$ :

- Seleção: é um processo de escolha de medicamentos, baseado em critérios epidemiológicos, técnicos e econômicos, estabelecidos por uma Comissão de Farmácia e Terapêutica (CFT), visando assegurar medicamentos seguros, eficazes e custo-efetivos com a finalidade de racionalizar seu uso, harmonizar condutas terapêuticas, direcionar o processo de aquisição, produção e políticas farmacêuticas. É a partir da seleção que são desenvolvidas as demais atividades;

- Programação: consiste em estimar quantidades a serem adquiridas para atendimento a determinada demanda dos serviços, por determinado período de tempo. A programação deve ser feita com base em uma Relação Nacional de Medicamentos Essenciais (RENAME) e Relação Municipal de Medicamentos Essenciais (REMUME), estabelecida e consensuada na etapa de seleção. Nessa lista, os medicamentos devem encontrar-se listados por nome genérico, forma farmacêutica e apresentação, e elencados, preferencialmente, pelo nível de complexidade no qual serão utilizados. A programação inadequada reflete diretamente sobre o abastecimento e o acesso ao medicamento;

- Aquisição: consiste num conjunto de procedimentos pelos quais se efetiva o processo de compra dos medicamentos, de acordo com uma programação estabelecida, com o objetivo de suprir necessidades de medicamentos em quantidade, qualidade e menor custo-efetividade e manter a regularidade do sistema de abastecimento. A programação da aquisição deve responder: O que comprar? Para quem? Modo de comprar? Quanto? Quando? Como comprar?;

- Armazenamento: é o conjunto de procedimentos técnicos e administrativos que tem por finalidade assegurar as condições adequadas de recepção, armazenamento, conservação e de um controle de estoque eficaz, bem como garantir a disponibilidade dos medicamentos em todos os locais de atendimento ao usuário;

- Distribuição: consiste no suprimento de medicamentos às unidades de saúde, em quantidade, qualidade e tempo oportuno. A distribuição de medicamentos deve garantir rapidez e segurança na entrega, eficiência no controle e informação; 


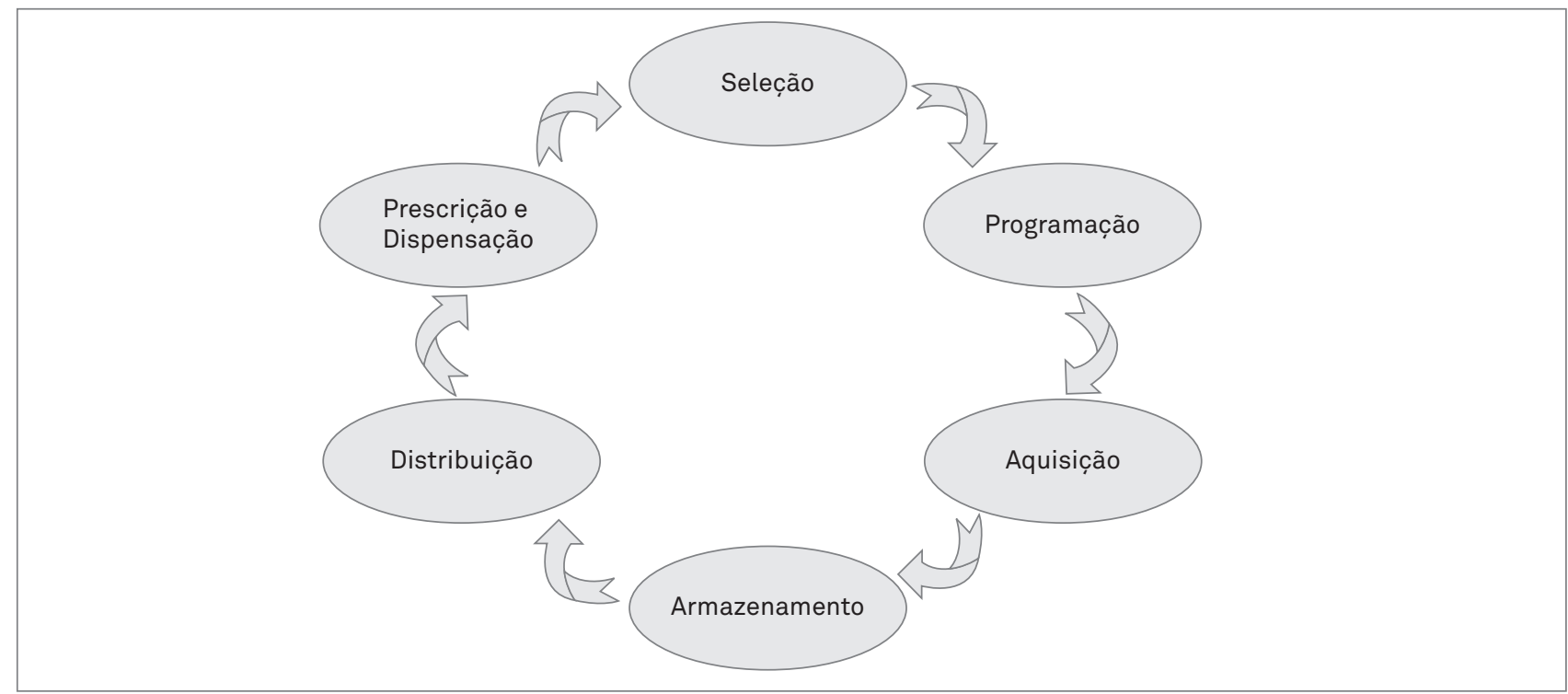

Figura 1: Ciclo da Assistência Farmacêutica (adaptado de Santos4)

- Prescrição: instrumento no qual se apoia a dispensação. Conforme a PNM, a 'prescrição de medicamentos' é o "ato de definir o medicamento a ser consumido pelo paciente, com a respectiva dosagem e duração do tratamento. Em geral, esse ato é expresso mediante a elaboração de uma receita médica”. A 'receita' é, portanto, o documento formal e escrito que estabelece o que deve ser dispensado ao paciente e como o paciente deve usá-lo;

- Dispensação: é o ato profissional farmacêutico, que consiste em proporcionar um ou mais medicamentos, em resposta à apresentação de uma receita elaborada por um profissional autorizado. Neste ato o farmacêutico exerce a Atenção Farmacêutica.

Atenção Farmacêutica é a interação direta do farmacêutico com o usuário, visando uma farmacoterapia racional e a obtenção de resultados definidos e mensuráveis, voltados para a melhoria da qualidade de vida ${ }^{5}$.

O farmacêutico ocupa papel-chave na Assistência Farmacêutica, na medida em que é o único profissional da equipe de saúde que tem sua formação técnico-científica fundamentada na articulação de conhecimentos das áreas biológicas e exatas, porém sua inserção ocorre de forma gradativa e heterogênea, encontrando-se, hoje, muito aquém das necessidades, tanto do ponto de vista quantitativo, quanto qualitativo ${ }^{3,6}$

Mundialmente, evidencia-se o papel do farmacêutico como profissional da área da saúde, cujas funções devem ser voltadas para o uso racional de medicamentos, visando o bem-estar da população e a redução dos gastos desnecessários ${ }^{6}$.

Os resultados do estudo de Silva Júnior e Nunes ${ }^{1}$ mostram que é necessário fazer ajustes nas diversas etapas do Ciclo da Assistência Farmacêutica.

$\mathrm{Na}$ etapa de seleção, atividade mais importante do ciclo, não há existência da Comissão de Farmácia e Terapêutica (CFT), nem da REMUME, comprometendo a seleção dos medicamentos necessários para o município.

$\mathrm{Na}$ etapa de programação, embora admitam realizar, não é feito um controle de estoque adequado, comprometendo o abastecimento e acesso dos medicamentos.

$\mathrm{Na}$ etapa de armazenamento, a etapa mais problemática do município de Petrolina ( $\mathrm{PE})^{1}$, as condições do espaço físico e infraestrutura não asseguram condições adequadas na conservação dos medicamentos, foram encontrados locais com infiltração, umidade, controle inadequado ou inexistente de temperatura dos produtos termolábeis, ausência de proteção contra insetos e roedores, entre outros.

Na etapa de distribuição, não há uma central que mantém e abastece de modo dinâmico os estoques de medicamentos com qualidade e na quantidade adequada para cada Unidade de Saúde da Família.

Por fim, na etapa de prescrição e dispensação, a dispensação é realizada, geralmente, por um auxiliar de enfermagem, o qual não é capacitado, tecnicamente, pelo farmacêutico, favorecendo a uma maior incidência de Problemas Relacionados a Medicamentos (PRM) no município.

A Assistência Farmacêutica no serviço público tem ainda um grande caminho a percorrer. A necessidade de tratar esse tema com a devida responsabilidade pelos gestores de saúde é imprescindível. Para isso, a qualificação do profissional farmacêutico, assumindo suas funções de gestor do ciclo da Assistência Farmacêutica, assim como seu papel na atenção farmacêutica, é determinante. 


\section{REFERÊNCIAS}

1. Silva Júnior EB, Nunes LMN. Avaliação da farmacêutica na atenção primária no município de Petrolina-Pernambuco. Arq Bras Ciên Saúde. 2012;37(2):65-9.

2. Brasil. Ministério da Saúde. Portaria n 3.916, de 30 de outubro de 1998. Política Nacional de Medicamentos. Diário Oficial da República Federativa do Brasil. Brasília, DF; 1998 Out 30.

3. Brasil. Ministério da Saúde. Secretaria de Ciência, Tecnologia e Insumos Estratégicos. Departamento de Assistência Farmacêutica e Insumos Estratégicos. Assistência farmacêutica na atenção básica: instruções técnicas para sua organização/Ministério da Saúde, Secretaria de Ciência, Tecnologia e Insumos Estratégicos, Departamento de Assistência Farmacêutica e Insumos Estratégicos. 2a ed. Brasília: Ministério da Saúde; 2006. Disponivel em: http://www.ensp.fiocruz.br/portal-ensp/judicializacao/pdfs/283.pdf. Acesso em: 27 jun. 2012.

4. Santos SCM. Melhoria da equidade no acesso aos medicamentos no Brasil:os desafios impostos pela dinâmica da competição extra-preço [Dissertação de Mestrado]. Rio de Janeiro: Fundação Oswaldo Cruz, Escola Nacional de Saúde Pública; 2001.180 p.

5. Conselho Nacional de Saúde. Resolução n 338, de 6 de maio de. Disponível em: http://portal.saude.gov.br/portal/arquivos/pdf/resol_cns338.pdf. Acesso em: 26 jun. 2012.

6. Mestriner DCP. O farmacêutico no serviço público de saúde: a experiência do Município de Ribeirão Preto - SP. 2002 [Dissertação de Mestrado]. Ribeirão Preto: Faculdade de Medicina de Ribeirão Preto, Universidade de São Paulo; 2003. 